Karen Manarin, MOUNT ROYAL UNIVERSITY, kmanarin@mtroyal.ca Christine Adams, UNIVERSITY OF TASMANLA, c.adams@utas.edu.au Richard Fendler, GEORGIA STATE UNIVERSITY, rfendler@gsu.edu Heidi Marsh, GEORGE BROWN COLLEGE, heidi.marsh@georgebrown.ca Ethan Pohl, QUEEN'S UNIVERSITY, epohl5497@gmail.com Suzanne Porath, KANSAS STATE UNIVERSITY, sporath@ksu.edu Alison Thomas,DOUGLAS COLLEGE, dralisonthomasa@shaw.ca

\title{
Examining the Focus of SoTL Literature-Teaching and Learning?
}

\section{ABSTRACT}

Although the Scholarship of Teaching and Learning (SoTL) claims to focus on student learning, some have argued that SoTL studies often adopt a narrow view of learning and focus more on teaching than on learning. In this paper, we explore whether teaching is the primary focus of recent articles published from 2013-2017 in three international, self-identified SoTL journals: Teaching and Learning Inquiry: The ISSOTL Journal( TLA), The International Journal for the Scholarship of Teaching and Learning (ijSOTL), and The Journal of the Scholarship of Teaching and Learning (JoSOTL). Based on our analysis of the 299 empirical articles, we argue that they portray SoTL as a field focused primarily on teacher activity rather than student learning, despite efforts to broaden its scope.

\section{KEYWORDS}

SoTL, literature review, teaching, learning

\section{INTRODUCTION}

In the inaugural issue of Teaching and Learning Inquiry, Peter Felten (2013) identified the first principle of good practice in the Scholarship of Teaching and Learning (SoTL) as "inquiry into student learning." However, as Carolin Kreber (2013b) noted in the same issue, learning is often narrowly defined in SoTL: "one can observe a strong tendency for the SoTL to be interpreted as empirical inquiries into the relationship between instructional strategy and the students' learning of the material taught" (12). This paper explores the tension between these two claims by examining a set of empirical articles published in general SoTL journals.

The Scholarship of Teaching was not initially conceptualized as a way to produce or disseminate empirical enquiries of any kind. Rather, the initial taxonomy created by Boyer in Scholarship Reconsidered: Priorities of the Professoriate (1990) focused on the Scholarship of Teaching as a way to redress the unequal reward system of academia by focusing on the professionalism required to teach well: what some would now call "scholarly teaching" (Potter and Kustra 2011; Richlin and Cox 2004). However, within a decade, the movement had shifted to emphasize the importance of sharing insights beyond the individual classroom through conducting and publishing peer reviewed research (Hutchings 
and Shulman 1999). Reflecting the paradigm shift from 'instruction' to 'learning' (Barr and Tagg 1995), the movement added the word learning to its name, and a number of SoTL journals were born, including The Journal of the Scholarship of Teaching and Learning (JoSoTL) in 2001, The International Journal for the Scholarship of Teaching and Learning (ijSOTL) in 2007, and more recently, Teaching and Learning Inquiry: The ISSOTL Journal (TLI) in 2013. However, some critics have argued that learning has been given less attention than teaching in SoTL publications (see, for example, Boshier 2009; Boshier and Huang 2008; Garritz 2010; Kreber 2005).

Focusing on both teaching and learning in SoTL has been a challenging task, in part because learning is difficult to define, and consequently also to measure. In their influential article, Barr and Tagg (1995) proposed that rather than focusing on knowledge transfer, the new "learning paradigm" should focus on a much broader conception of how we foster learning by "creat[ing] environments and experiences that bring students to discover and construct knowledge for themselves" (15). Similarly Biggs (1999) suggested that

Learning is ... a way of interacting with the world. As we learn, our conceptions of phenomena change, and we see the world differently. The acquisition of information in itself does not bring about such a change, but the way we structure that information and think with it does (60).

For Barnett (2004) "learning implies a change in understanding and a change in one's relationship to the world" (248). So whereas the instruction paradigm viewed learning as acquiring more knowledge (learning about something), the learning paradigm focuses on the transformation of pre-existing knowledge (Meyer and Land 2005; Mezirow 1991). Schunk (2020) provides a very general, but useful, working definition of learning as "an enduring change in behavior, or in the capacity to behave in a given fashion, which results from practice or other forms of experience" (3). The focus is on an enduring change of behavior or capacity. Such change may occur in the learning environment as the result of a specific pedagogical approach or intervention, but the change in behavior or capacity is transferred to other contexts. Each of these definitions includes the idea of lasting change-whether behavioral, epistemological, or ontological.

Given the theoretical and methodological challenges of capturing the complexity of the learning process, we wanted to see to what extent recent debates within SoTL about defining and measuring learning have been reflected in its published research. Of course, publication of peer reviewed research is not the only or, indeed some would argue, the primary purpose of SoTL, but patterns in publication can provide glimpses into our assumptions about teaching and learning. In particular, we were keen to examine Kreber's assertion that most SoTL research employs a narrow conception of teaching and learning. Accordingly, we undertook a review of studies published in a sample of SoTL journals between 2013 and 2017. As Chick, Nowell, and Lenart (2019) note,

Beyond the ongoing efforts to define and theorize itself, the field needs this kind of rigorous inventory taking and analysis that maps the field to show the highly traveled questions, topics, methods, and areas where more work needs to be done, as well as who is doing the work (187).

In recent years Fanghanel, Pritchard, Potter, and Wisker (2015); Tight (2017); and Booth and Woollacott (2018) have all provided comprehensive reviews of the state of SoTL, examining 
institutional policy, impact, and domains of SoTL respectively. Divan, Ludwig, Matthews, Motley, and Tomljenovic-Berube (2017) examined the range of research methods employed in their sample of empirical research studies. In examining the range of research questions and approaches employed by SoTL researchers, our own analysis centres on the extent to which the primary focus is on the teacher and their pedagogy, or on students and their learning experience.

\section{METHOD}

\section{Review team}

Seven researchers from seven different higher education institutions participated in the analysis. We were brought together through the 2019 ISSOTL International Collaborative Writing Initiative, and so worked within the parameters of that program. Our institution types and national contexts are as broad as our disciplines which include business, sociology, psychology, education, and English.

\section{Selection of journals}

We deliberately chose TLI, JoSoTL, and ijSoTL because they include the idea of Teaching and Learning in their titles. Individuals new to SoTL may gravitate toward them, perhaps taking the articles published in them as exemplars for what SoTL should be. These generalist journals were also selected rather than disciplinary based journals such as Teaching Sociology or CBE Life Sciences Education because of the wide variety of SoTL work contained, with respect to the discipline studied, methodologies, and article types. We limited our review to 2013-2017, covering the first five years of publication of TLI. This limitation served to reasonably restrict the amount of literature that would need to be reviewed while also allowing us to capture a substantial picture of research and publication trends during this period. We coded 404 empirical and non-empirical articles; however, book reviews and editor introductions/notes were excluded.

\section{Article coding}

To begin, we discussed the categories, questions, and variables that would be useful for inclusion in the coding system. Variables included whether an article was empirical, and who was being discussed/observed (e.g. undergraduates). We also examined how data were collected. Data collection methods included:

- Classroom observation: a third party observing in the classroom

- Course artifacts: assignments generated for the course where more than the grade was analysed

- Grades: student scores on particular assignments, course grades and/or GPA

- Interviews/focus groups: conversations with research participants

- Pre-/post-tests: participants complete a learning task more than once for the purpose of research

- Course evaluations: formal, administratively sanctioned ratings of learning experiences by students

- Surveys: self-reported measures, that may contain questions about teaching effectiveness or engagement in the learning experience

- Other: data that did not fit into one of the categories above (e.g. attendance)

Additionally, we explored what was measured in the reviewed articles: 
- Conventional learning outcomes: course level learning outcomes or what students are expected to learn, including specific knowledge and practical skills

- Program level outcomes: the intended learning outcomes from a program

- Preference or satisfaction: how much a student likes one form of instructional design versus an alternative

- Graduate attributes: the overarching capabilities enabling successful graduate entry into a profession or workplace, including communication and problem-solving skills

- Engagement: perceived student interaction and psychological investment in, and effort toward learning

- Experience/Perception: a response to teaching, learning and/or curriculum whether self-reported or rated by others

- Confidence: measure of student self-belief, self-efficacy, and self-concept

- Attitude: positive or negative feelings toward some aspect of a learning experience in terms of its perceived relevance, value and/or difficulty.

We came to these categories and definitions through an iterative process. In order to standardize review practices, we discussed discrepancies in understanding and interpretation. Once all coding items and questions were agreed upon, they were aggregated into an online form to be completed for each article. Next, to test the adequacy of our coding scheme, each reviewer analyzed 10 articles and noted questions or observations that arose during that process. The group then met and discussed these and came to a consensus about any changes that were needed for the coding system. Two further iterations of this process followed, including re-coding those articles that had previously been analyzed using the updated coding system. At that point, substantial consensus was reached regarding the reliability of the coding system, and the entire dataset of articles was divided among reviewers and independently analyzed.

When approximately $75 \%$ of the articles were reviewed, each member analyzed the same 10 articles independently to check for coder consistency; we then consulted face-to-face on any discrepancies. Where we encountered challenges with regard to inter-rater reliability, we used several rounds of group norming to agree on specific definitions for some concepts and variables (e.g. agreeing to include focus groups with interviews for coding purposes). Each reviewer re-examined all of their previously coded articles, making changes accordingly. While this iterative process uncovered some initial differences in how we conceptualized our terms, resolving these allowed us to feel more confident about inter-rater reliability.

\section{Additional qualitative analysis}

During face-to-face discussions, we decided to supplement the data obtained from our initial coding process with a more inductive approach to ensure we weren't missing other elements (Saldana 2013). We returned to a subset of 70 articles and identified their primary topic (as opposed to the various different things they measured) using in vivo coding of their titles. We then sorted codes into eight overarching themes and coded each case in the entire data set according to the theme that most closely aligned with its primary focus. Two additional categories, institutional mission or future and coinquiry/students-as-partners, were introduced at this point to accommodate the few articles that did not 
fit elsewhere. One outlier that did not fit into any of these categories was identified and discarded from this part of the analysis. The eight thematic categories were the following:

- Instructor characteristics (e.g. faculty development)

- Student characteristics (e.g. confidence, preference)

- Course or program structure (e.g. online vs. face-to-face)

- Scholarship of Teaching and Learning (i.e. as a field or movement)

- Faculty/Student relationships (e.g. office hours, mentoring, policies)

- Assessment (e.g. exams, assignments)

- Instructional tool (involving a limited or bounded intervention e.g. clickers)

- Instructional approach (e.g. experiential, active or service learning)

- Co-inquiry/students-as-partners

- Institutional mission or future

We later combined 'instructional tool' and 'instructional approach' into one category, as it was difficult to make a distinction between the two in all cases.

Finally, we examined the authors' stated research questions in terms of sentence stems.

A research question identifies the focus of the study regardless of whether the methodology employed is qualitative, quantitative, or mixed methods (de Souza, Neri, and Costa 2016; Tashakkori and Creswell 2007). However, the ways researchers phrase their question suggest an inclination toward methods that explore, describe, explain, test, or develop ideas about the phenomenon under study. For example, particular sentence stems such as "How does..." or "What are..." tend to be associated with specific methodologies, analysis, and conclusions (Cronjé 2020). So as part of our analysis, we examined the sentence stems of the research questions provided by the authors of the studies. Using in vivo coding, the research questions were grouped by how the question was phrased, such as "What impact does have on __ ?" or "What are the benefits of __ ?" By reviewing these sentence-stem groupings, we found strong patterns in the focus of the study, data collected, forms of analysis, and reported results. Although we hadn't initially planned the additional analyses, they enabled us to triangulate our data, complementing our deductive or 'top-down' approach (based on our original coding-frame) with an inductive or 'bottom up' approach (thematic analysis of papers to determine broader categories and sentence stem analysis of research questions).

\section{FINDINGS}

For this paper, we focus on the empirical articles within our sample in which data collection and analysis play a central part. As in any field, purely theoretical articles also provide an important reflection of the current state of the SoTL movement; however, our initial goal was to assess evidence of the ways in which SoTL research was being designed and conducted. We were curious about Kreber's claim about empirical inquiries. Of the 404 journal articles coded, 299 were articles reporting empirical research (74\%) and 105 (26\%) were non-empirical. Whereas ijSoTL and JoSoTL had comparable ratios of empirical to non-empirical articles (slightly over 3:1), the ratio for articles published by $T L I$ over the same time-period was 3:2.

Through the iterative coding process, we found that the most common data source was students, particularly undergraduate students (included in $73.9 \%$ of articles), whilst the second most 
common was faculty (19.4\%). Graduates of programs were rarely considered in SoTL studies; they were data sources in only two of the articles we reviewed (See figure 1).

Figure 1. Data represented in percentages based on observations in 299 empirical articles. Please note that the numbers add up to more than $100 \%$ as 30 articles reported more than one data source.

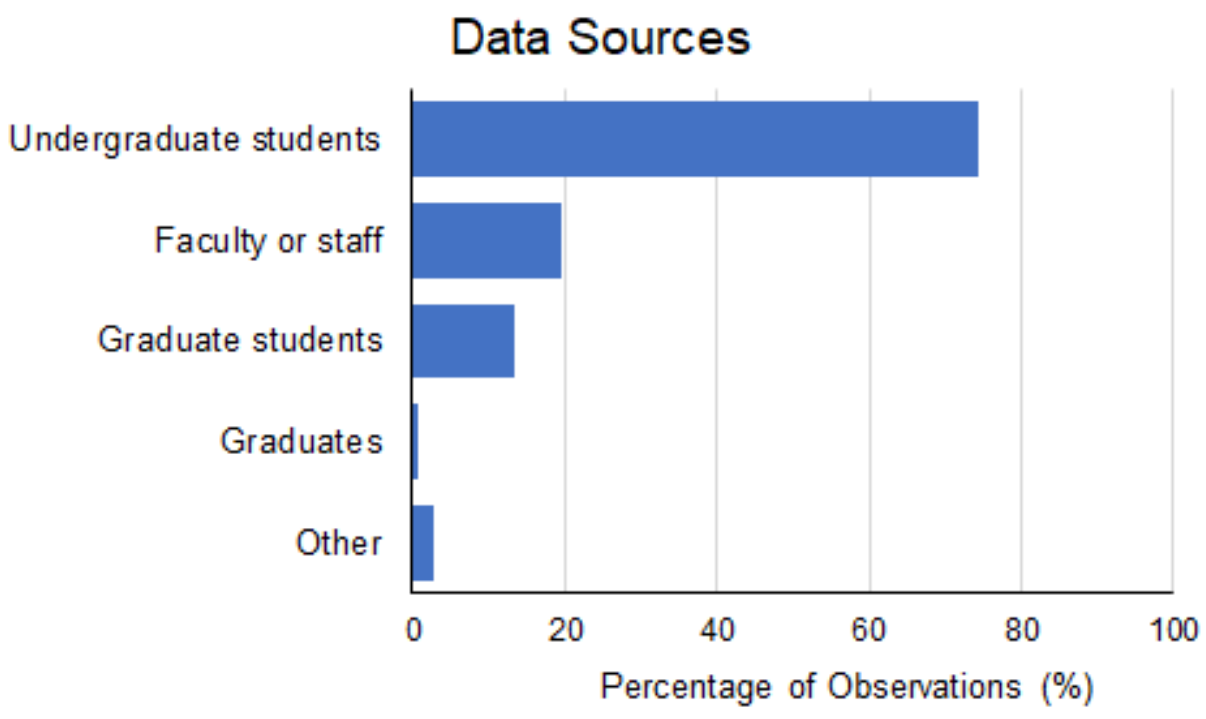

We also examined methods of data collection. Although surveys were by far the most commonly reported form of data collection employed in these studies (63.9\%), with interviews and focus groups the next most common method (26.1\%), a wide variety of other methods were also reported. Half of the studies $(50.2 \%)$ used more than one of these. Other measures of learning, whether course grades $(20.4 \%)$, course artifacts such as essays (17.4\%), pre- and post-tests (9.7\%), or classroom observations by a third party $(4.3 \%)$, were far less common (see figure 2 ). 
Figure 2. Data represented in percentages based on observations in 299 empirical articles. Please note that the numbers add up to more than $100 \%$ as many articles reported more than one method of data collection.

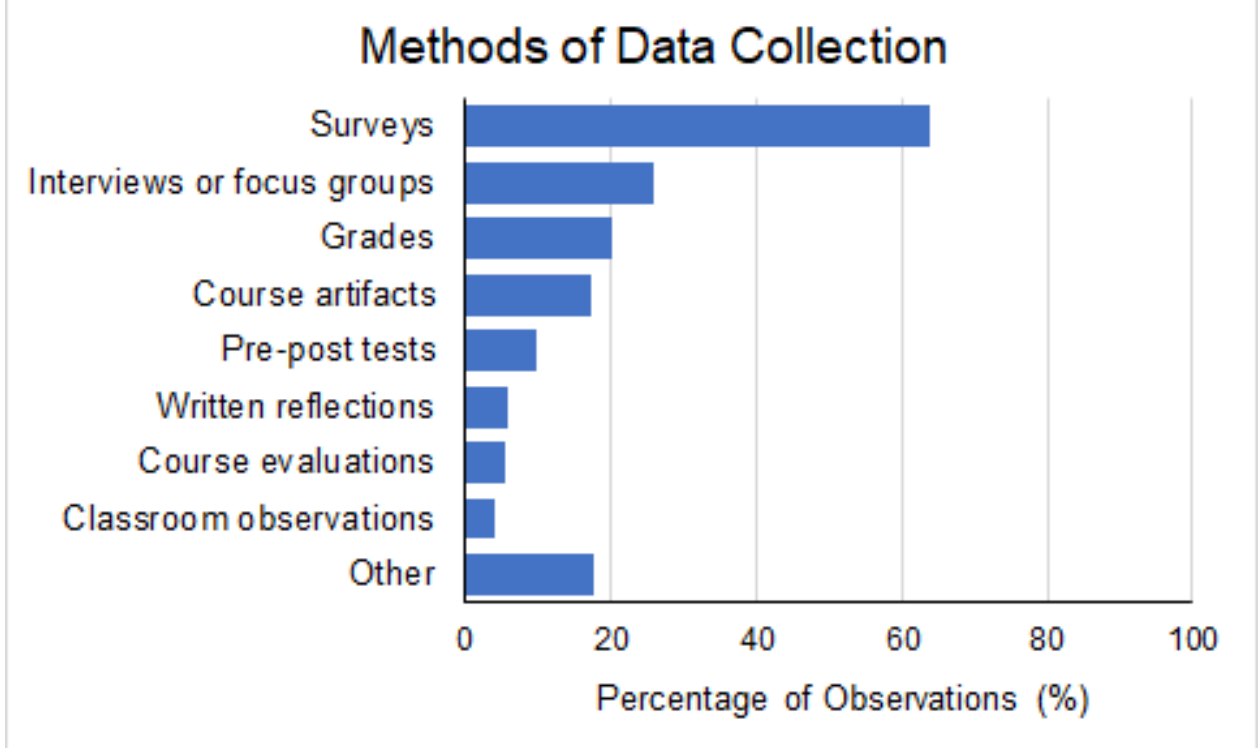

We also examined what was measured with these tools. Consistent with the predominance of articles focusing on undergraduate students, many studies measured conventional learning outcomes (41.8\%), student satisfaction (32.1\%), or other constructs (54.2\%), such as engagement, perception, attitude, confidence, motivation, or cultural appreciation. Few articles focused on either program level outcomes $(11 \%)$ or graduate attributes (12\%) (see figure 3 ). 
Figure 3. Data represented in percentages based on observations in 299 empirical articles. This figure includes constructs measured in at least 10 articles. Please note that a single article will be represented more than once in the chart if it measured more than one category.

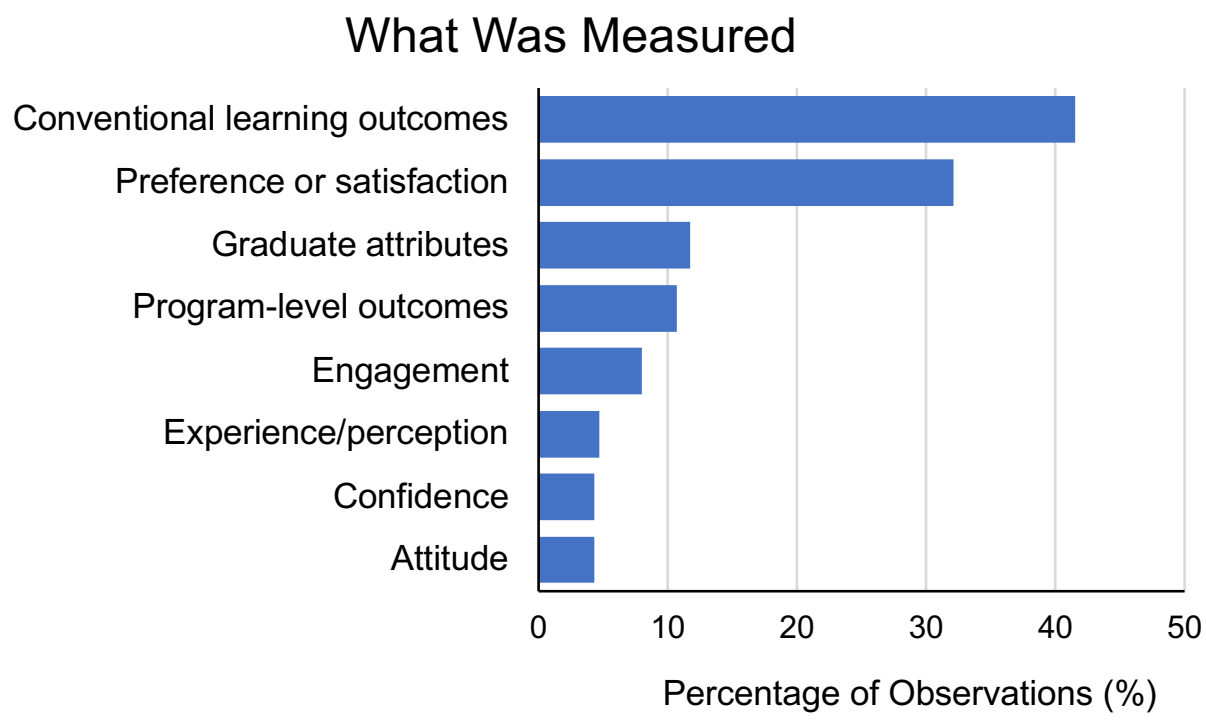

We also included a broader question about whether the article explored the impact of a specific pedagogical approach. Importantly, we found that nearly half of the empirical articles (49.2\%) examined this variable, whether looking at this impact in terms of learning outcomes, student satisfaction, response to instruction, or other constructs.

Our second set of findings involved the analysis of the focus of each article (see figure 4). This showed that $42.1 \%$ of empirical articles focused primarily on investigating the impact of particular instructional approaches (for example, experiential learning) or instructional tools (such as use of clickers) on student learning or satisfaction. In addition, $24.1 \%$ of articles focused directly on student learning characteristics, with another $13.7 \%$ focusing on course or program structure and $7.4 \%$ focusing on instructor characteristics. 
Figure 4. Data represented in percentages based on observations in 299 empirical articles. Eight articles are represented more than once on the chart.

\section{Focus of Articles}

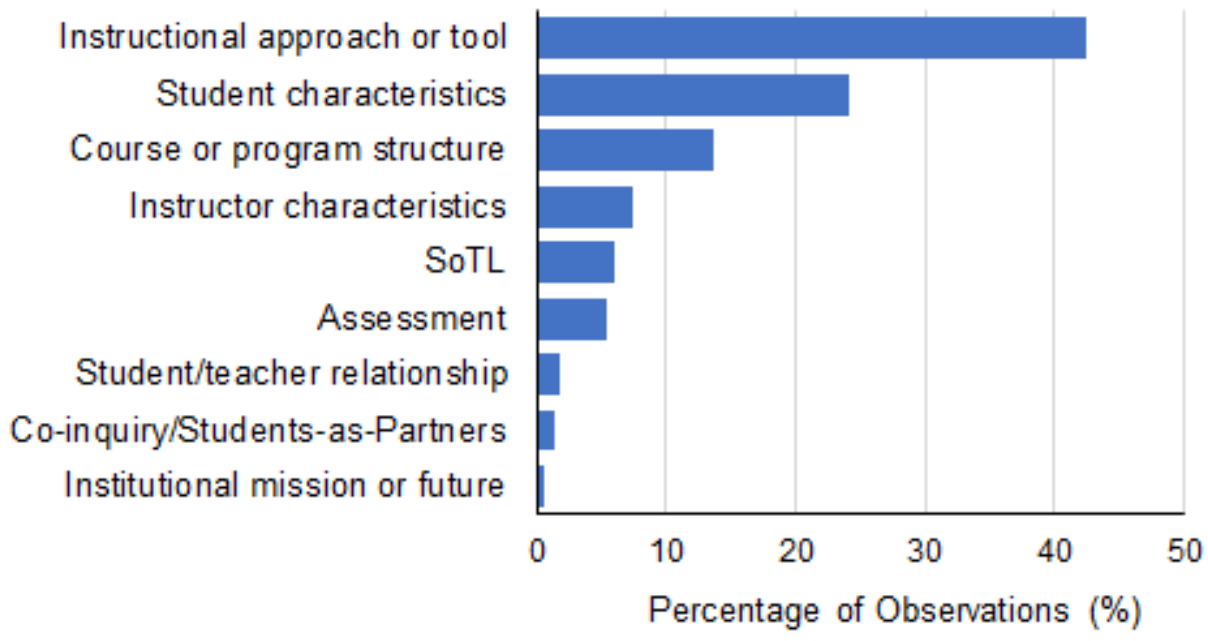

Our third set of findings was derived through stem analysis of the research questions. This confirmed that the focus of many articles was on the instructional approach or tool. The most common sentence framing for research questions included: "Do/Does do ?" or "How do perceive/experience/define ___?" or "What is the relationship between ___ and __? When all sentence frames were classified, we found five common investigation designs across the majority of the empirical studies:

- How does an instructional practice impact the student? (The impact might be on a perception, disposition, feeling, or performance.)

- What are the experiences/beliefs/perceptions of faculty or students about a specific event, phenomenon, pedagogy, or tool?

- Is a specific practice or pedagogy effective? And, to what extent?

- What are the similarities and differences between A and B?

- What is the relationship between $A$ and B?

The most common pattern of research question (employed in $45 \%$ of the articles analysed) followed the structure of implementing an instructional practice or tool and evaluating the impact on a particular student characteristic (i.e., test performance, satisfaction). In most cases the impact was assessed using quantitative measures, and the main focus was again on the effect of the pedagogy rather than on the quality of the learning.

In summary, using three different analytic approaches (initial coding of articles identifying those assessing the impact of a specific pedagogical approach; thematic analysis of article title; and analysis of the sentence stems of research questions), we found that almost half of the empirical articles in our sample focused on assessing the impact of specific teaching practices, rather than on other dimensions of student learning. At the same time, however, we noted that the majority of articles used more than one measure to judge the effectiveness of these teaching practices. 


\section{DISCUSSION}

This paper focuses on the empirical articles published in three general SoTL journals from 20132017. The findings about data sources and methods of data collection are comparable with those of Divan, Ludwig, Matthews, Motley, and Tomljenovic-Berube (2017) in two important respects. First, the vast majority of the studies we analyzed (87.6\%) collected data from undergraduate students, compared to $83.9 \%$ of those analyzed by Divan et al. Further, in both studies surveys were found to be the most common form of data collection (63.9\% of articles in our study and 71\% in Divan et al). In our sample most studies focused on specific undergraduate courses, and the impact of pedagogical interventions on knowledge transfer using a 'snapshot' approach, as described in Divan, Ludwig, Matthews, Motley, and Tomljenovic-Berube (2017) and Matthews, Divan, John-Thomas, Lopes, Ludwig, Martini, Motley, and Tomljenovic-Berube (2013).

Some articles using a pre- and post-test approach attempt to demonstrate change over a very limited time period; however, it is difficult to determine if such change would be lasting. Fewer than $1 \%$ of studies focused on graduates and any evidence of enduring change resulting from their learning experiences. Yet we know that significant learning takes time as it involves not only knowledge acquisition, but also developing new ways of thinking and changing attitudes toward knowledge and agency (Barber, King, and Baxter Magolda 2013; Baxter Magolda and Taylor 2015; Nilson 2013). If learning is defined as enduring change (Barnett 2004; Biggs 1999; Schunk 2020), these studies often cannot demonstrate change will persist. This remains a significant drawback of SoTL when it involves an instructor investigating student learning in their own classroom. No matter how good the study, it cannot demonstrate enduring change within that limited context and time-frame. In order to better understand student learning, we need to work together to promote, engage in, and share crossdisciplinary, longitudinal research that more closely reflects the way we conceptualize learning.

We also noted many studies use indirect evidence of learning, specifically, self-reported data (such as perceptions of learning) gathered through surveys, focus groups, and interviews. While it can be important in its own right to find out what students believe they are learning, Bowman (2014) argues that self-reported learning gains are unreliable as a measure of student learning and are more likely to be an indicator of student satisfaction. The reliance on self-reported data when it is not accompanied by more direct measures of learning is particularly concerning in the case of studies measuring conventional learning outcomes. Data collection methods are best aligned with the research purpose (Mueller 2018), and so SoTL practitioners seeking to assess student learning should also use some existing, direct, measures of learning, imperfect though these may be.

For most classroom settings, these existing measures of learning include grades and assignments. Most institutions have the broad requirement to assess student achievement of course learning outcomes on a numerical scale (grades); however, instructors also have access to learning artifacts like student essays or problem sets, evidence of authentic and transformational learning experiences through work-integrated learning, and projects that demand the application of learning. In the classroom setting, learning is typically measured through artifacts such as these and on student performance on tests or examinations, all of which are ultimately represented with grades. However, relatively few of the studies in the sample (fewer than 20\%) used any of these artifacts as data. It is worth noting that SoTL practitioners - as educators - routinely evaluate their students' learning using these more direct measures, but many change to indirect measures such as surveys, when in the arena of "SoTL research." 
Accordingly, these artifacts could be explored in SoTL projects, recognizing that examining a set of artifacts for evidence of a particular outcome in a SoTL project involves more than recording grades (Manarin 2018). For example, examining a student's work for evidence of change over the course of a term is a different activity than measuring that student's work against a set of pre-determined learning outcomes (Thomas 2019).

Of course, learning involves more than cognitive development that could be assessed through assignments and recorded through grades. Ideally, the learning environment should also stimulate student motivation, engagement, self-efficacy, and resilience. Some studies in our corpus seemed to be using these constructs as indirect proxies of student learning. Although students are more likely to learn if they are engaged or feel confident (Ryan and Deci 2000; Wigfield and Eccles 2000), many articles in our sample do not make these connections to learning theory explicit in part because they do not define what learning means in a particular context. Given widespread recognition that there are multiple ways of learning in different domains (Adams 2016; Barnett 2009; Gurm 2013), it would be helpful for SoTL practitioners to pay closer attention to the various ways the subject matter can come to be understood, what counts as understanding, and how individual students experience the subject in the specific context under study (Scott 2013). However, all too often the default in these studies of teaching and learning seems to be to avoid grappling with defining learning and instead to focus on the teaching.

By far the most common focus in our sample was on instructional tool or approach, confirming Kreber's (2013b) claim that SoTL focuses on "empirical inquiries into the relationship between instructional strategy and the students' learning of the material taught." Analyzing sentence stems of the research questions confirms this observation. In Hutchings' (2000) taxonomy, many of these studies focus on "what works" questions and the instructor's role rather than exploring the complexity of student learning through "what is" happening, let alone considering "visions of the possible" in measuring teaching and learning or formulating new conceptual frameworks. We cannot really proceed to exploring "what works" without starting from a better definition of what counts as student learning and from that gaining a better understanding of "what is" - and yet because that is so much harder to quantify, it appears that, collectively, we have largely avoided it. In our SoTL work, we have the possibility of adopting more complex and detailed ways of examining student learning, yet our analysis reveals a somewhat limited range of approaches and an over-reliance on self-reported learning obtained via student surveys.

Though our study provided rich data, our sample consisted of articles from just three mainstream, North American-based SoTL journals, over a five-year period (2013-2017). Both the choice of journals and the particular time-period present limitations to our findings. With respect to the timeframe, SoTL has continued to evolve in new ways over the past three years, and studies addressing different facets of learning may therefore be more prevalent now than they were in the period we studied. Certainly, it would be interesting to compare these findings with the next five years of articles from these journals to see whether a more holistic view of learning is developing and whether indirect measures of learning have been supplemented by more nuanced accounts of how and why learning happens.

Similarly, our selection of journals may not be capturing the full variety of articles published in those years across the whole spectrum of SoTL publications. It would therefore be useful to compare the findings presented here with analysis of articles published in other journals that focus on teaching and learning, but which do not explicitly label themselves as SoTL (like College Teaching, The Journal of 
Excellence in College Teaching, or Higher Education Research and Development), as well as those that are aimed at a more specialised audience, such as Teaching Sociology. Indeed, one illustration of the limitations of our sample was the surprisingly limited evidence we found in our data set of the growing field of work involving 'students-as-partners,' where learning from and with each other in a mutually supportive environment is investigated. This may be a function of the time period we studied or of other publication options, such as the 2017 launch of a specialist journal (International Journal for Students as Partners) and thereby highlights the differences that may be found between what is published in mainstream and specialist journals.

For the purposes of this paper, we chose to focus exclusively on the empirical articles of our corpus and have provided only a general overview of our findings. Our findings would likely have been different if we had included the non-empirical articles. In further analysis of this dataset, we propose to take a deeper dive into the empirical articles, exploring a taxonomy of research questions, the types of surveys or interviews used, and the trends over time and by journal. However, we also want to explore the 105 theoretical and argumentative essays published in our sample of journals and identify the themes, concerns, and preoccupations within SoTL that they articulate. Some of the non-empirical articles contain rich, meaningful, and provocative discussions about student learning, and we hope to explore this material further in a future analysis.

Beyond reviews of published materials, however, we also encourage consideration of the role of SoTL research more broadly in developing a meaningful culture of learning for both faculty and students. For example, Bernstein (2010) argues that SoTL practitioners range across a spectrum from those engaging in reflection on teaching and learning for their own purposes to those conducting rigorous educational research to advance knowledge. In contradistinction to much traditional educational research, SoTL practitioners often investigate their own classrooms from disciplinary perspectives, perhaps with limited resources or even desire to extend that research further, leading to many local studies. These smaller scale studies can be seen as a criticism (i.e. evidence of enduring change is difficult to find) or a strength (i.e. reflective practitioners improve their practice) of SoTL. Kreber (2013a) argues "engagement in the scholarship of teaching and learning involves asking not only 'Does it work?' but 'Is it right?' For whom? Why? (159). For example, we might question whether our present methods of assessing student learning in higher education actually encourage learning as enduring change. To that end, we urge faculty to partner with students to explore how both faculty and students define learning and what enables both faculty and students to learn.

\section{CONCLUSION}

Our evidence suggests that empirical SoTL articles published from 2013-2017 continued to emphasize "what works" in terms of teacher activity rather than "what is" happening in terms of student learning. Perhaps this imbalance between attention to teaching and to learning occurs because learning is not well defined in these studies: we often appear to rely on conventional assumptions that learning equates to student success and mastery of specific course learning outcomes rather than paying attention to the specific changes that have occurred in student understanding. In this paper we have identified a consensus in the literature around the importance of definitions that focus on change in understanding, and Miller-Young and Yeo (2015) offer a starting place for SoTL practitioners interested in becoming familiar with a broad range of learning theories and expanding the range of questions we might ask about our students' learning. 
In terms of application, SoTL practitioners could explore and define learning as making new meaning of experiences and could look beyond the context of a single course, to focus on the capacity of students to enact change in their behaviours in differing contexts. Hutchings, Huber, and Ciccone (2011) argue that

If learning can be likened to an iceberg, with only a portion visible above the water, the scholarship of teaching and learning challenges teachers to get at what's beneath the surface, unseen, and only vaguely understood. As such it is work that requires (in addition to courage) not only more evidence of learning, but different kinds (32).

Looking for different kinds of evidence, we could accordingly pay more attention to qualitative dimensions of learning as revealed in student artifacts like course portfolios, essays, or problem sets. For example, we might be able to see evidence of perseverance, willingness to take risks, or creativity, even if the specific learning outcome was not achieved. Both Threshold Concept and the Decoding the Disciplines approaches offer insights into student learning and suggestions for ways gathering evidence of this (Meyer and Land 2005; Pace and Middendorf 2004). We could also try to think beyond a single pedagogical technique or practice and its short-term impact. Measuring learning across courses and paying attention to students' prior understanding of deep structures and assumptions of a field will help us articulate how students develop new learning. As Felten (2013) notes, faculty often start their SoTL projects with what Bass (1999) called "a teaching problem;" yet perhaps that only gets us so far. Bass (2020) revisits that concept to argue that "We need to think of the problem of learning —and by implication, the problem of higher education — as a complex, wicked problem ... rather than a tame or solvable one." As graduates engage in an increasingly complex world, there is an important role for the scholarship of teaching and learning to move beyond the scholarship of teaching to explore more fully the wondrous, messy world of student learning.

\section{ACKNOWLEDGEMENTS}

We would like to thank the 2019 ICWG leaders: Aysha Divan, Phillip Motley, and Lauren Scharff. We would also like to thank the anonymous reviewers for their thoughtful comments.

Karen Manarin, PhD, is Professor of English at Mount Royal University (CAN).

Christine Adams, PhD, is a teaching and learning academic in the College of Science and Engineering at the University of Tasmania (AUS). She does research in work-integrated learning and graduate employability. Orcid:0000-0001-5362-654.

Richard Fendler, PhD, is a clinical Associate Professor of Finance in the Robinson College of Business at Georgia State University (USA).

Heidi Marsh, PhD, is the Director of Scholarship of Teaching and Learning (SoTL) at Humber Institute of Technology and Advanced Learning (CAN).

Ethan Pohl is a PhD candidate in Sociology at Queen's University (CAN). 
Suzanne Porath, PhD, is an Assistant Professor in Curriculum and Instruction at Kansas State University (USA). Orcid: 0000-00033158-2958.

Alison Thomas, PhD, taught sociology at Douglas College (CAN) until her retirement in 2020.

\section{REFERENCES}

Adams, Christine A. 2016. "The Road Less Travelled: A Critical Realist Model for Graduate Attribute Development in Higher Education." PhD diss., University of Tasmania.

Barber, James P., Patricia M. King, and Marcia B. Baxter Magolda. 2013. "Long Strides on the Journey toward SelfAuthorship: Substantial Developmental Shifts in College Students' Meaning Making." The Journal of Higher Education 84, no. 6: 866-96. https://doi.org/10.1080/00221546.2013.11777313.

Barnett, Ronald. 2004, “Learning for an Unknown Future." Higher Education Research and Development 23, no. 3: 247-60. https://doi.org/10.1080/07294360.2012.642841

Barnett, Ronald. 2009. "Knowing and Becoming in the Higher Education Curriculum." Studies in Higher Education 34, no. 4: 429-40. https://doi.org/10.1080/03075070902771978.

Barr, Robert B., and John Tagg. 1995. "From Teaching to Learning: A New Paradigm in Undergraduate Education." Change 27, no. 6: 13-25.

Bass, Randy. 1999. "The Scholarship of Teaching: What's the Problem." Inventio: Creative Thinking about Learning and Teaching 1, no. 1.

Bass, Randall. 2020. "What's the Problem Now?" To Improve the Academy: A Journal of Educational Development 39, no. 1. http://doi.org/10.3998/tia.17063888.0039.102.

Baxter Magolda, Marcia, and Kari Taylor. 2015. "Developing Self-Authorship in College to Navigate Emerging Adulthood. In The Oxford Handbook of Emerging Adulthood, edited by Jeffrey J. Arnett, 299-315.

Bernstein, Daniel. 2010. "Finding Your Place in the Scholarship of Teaching and Learning." International Journal of SoTL 4, no. 2: Article 2. https://doi.org/10.20429/ijsotl.2010.040204.

Biggs, John. 1999. "What the Student Does: Teaching for Enhanced Learning." Higher Education Research and Development 18, no. 1: 57-75. https://doi.org/10.1080/0729436990180105.

Booth, Shirley, and L. C. Woollacott. 2018. "On the Constitution of SoTL: Its Domains and Contexts." Higher Education 75, no. 2: 537-51. https://doi.org/10.1007/s10734-017-0156-7.

Boshier, Roger. 2009. "Why is the Scholarship of Teaching and Learning Such a Hard Sell?" Higher Education Research and Development 28, no. 1: 1-15. https://doi.org/10.1080/07294360802444321.

Boshier, Roger, and Yan Huang. 2008. "In the House of the Scholarship of Teaching and Learning (SoTL), Teaching Lives Upstairs and Learning in the Basement." Teaching in Higher Education 13, no. 6: 645-56. https://doi.org/10.1080/13562510802452368.

Bowman, Nicholas A. 2014. "The Meaning and Interpretation of College Student Self-Reported Gains." In Methodological Advances and Issues in Studying College Impact, edited by Nicholas A. Bowman and Serge Herzog, 59-68. San Francisco, California: Jossey-Bass.

Boyer, Ernest L. 1990. Scholarship Reconsidered: Priorities of the Professoriate. Princeton, NJ: Carnegie Foundation for the Advancement of Teaching.

Felten, Peter. 2013. "Principles of Good Practice in SoTL." Teaching and Learning Inquiry 1, no. 1. https://doi.org/10.20343/teachlearninqu.1.1.121.

Chick, Nancy, Lorelli Nowell, and Bartlomiej Lenart. 2019. "The Scholarship of Teaching and Learning: A Scoping Review Protocol." Teaching \& Learning Inquiry7, no. 2. http://doi.org/10.20343/teachlearninqu.7.2.12.

Cronjé, Johannes C. 2020. "Designing Questions for Research Design and Design Research in e-Learning." The Electronic Journal of e-Learning 18, no. 1: 13-24.

De Souza, Francislê N., Dayse C. D. S. B. Neri, and António P. Costa. 2016. "Asking Questions in the Qualitative Research Context." The Qualitative Report 21, no. 13: 6-18. https://nsuworks.nova.edu/tar/vol21/iss13/2.

Divan, Aysha, Lynn O. Ludwig, Kelly E. Matthews, Phillip M. Motley, and Ana M. Tomljenovic-Berube. 2017. "Survey of Research Approaches Utilised in the Scholarship of Teaching and Learning Publications." Teaching \& Learning Inquiry 5, no. 2: 16-29. https://doi.org/10.20343/teachlearninqu.5.2.3. 
Fanghanel, Joëlle, Jane Pritchard, Jacqueline Potter, and Gina Wisker. 2015. "Defining and Supporting the Scholarship of Teaching and Learning (SoTL): A Sector-Wide Study." York: Higher Education Academy. Retrieved from https://www.heacademy.ac.uk/knowledge-hub/defining-and-supporting-scholarshipteaching-and-learning-sotl-sector-wide-study.

Garritz, Andoni. 2010. "Personal Reflection: Pedagogical Content Knowledge and the Affective Domain of Scholarship of Teaching and Learning." International Journal for the Scholarship of Teaching and Learning 4, no. 2: Article 26.

Gurm, Balbir K. 2013. "Multiple Ways of Knowing in Teaching and Learning." International Journal for the Scholarship of Teaching and Learning 7, no. 1: Article 4. https://doi.org/10.20429/ijsotl.2013.070104.

Hutchings, Pat. 2000. Opening Lines: Approaches to the Scholarship of Teaching and Learning. Menlo, CA: Carnegie.

Hutchings, Pat, and Lee S. Shulman. 1999. "The Scholarship of Teaching: New Elaborations, New Developments." Change: The Magazine of Higher Learning 31, no. 5: 10-15. https://doi.org/10.1080/00091389909604218.

Hutchings, Pat, Mary T. Huber, and Anthony Ciccone. 2011. Scholarship of Teaching and Learning Reconsidered. Stanford, CA: Jossey-Bass.

Kreber, Carolin. 2005. "Charting a Critical Course on the Scholarship of University Teaching Movement." Studies in Higher Education 30, no. 4: 389-405.

Kreber, Carolin. 2013a. Authenticity in and through Teaching in Higher Education: The Transformative Potential of the Scholarship of Teaching. London: Routledge.

Kreber, Carolin. 2013b. "The Transformative Potential of the Scholarship of Teaching." Teaching and Learning Inquiry 1, no. 1. https://doi.org/10.20343/teachlearninqu.1.1.5.

Manarin, Karen. 2018. "Close Reading: Paying Attention to Student Artifacts." In SoTL in Action: Illuminating Critical Moments of Practice, edited by Nancy Chick, 100-108. Sterling, VA: Stylus.

Matthews, Kelly E., Aysha Divan, Nicole John-Thomas, Valerie Lopes, Lynn O. Ludwig, Tanya S. Martini, Phillip Motley, and Ana M. Tomljenovic-Berube. 2013. "SoTL and Students' Experiences of Their Degree-Level Programs: An Empirical Investigation." Teaching and Learning Inquiry 1, no. 2. https://doi.org/10.20343/teachlearninqu.1.2.75.

Meyer, Jan H. F., and Ray Land. 2005. “Threshold Concepts and Troublesome Knowledge (2): Epistemological Considerations and a Conceptual Framework for Teaching and Learning." Higher Education 49, no. 3: 373-88. https://doi.org/10.1007/s10734-004-6779-5.

Mezirow, Jack. 1991. Transformative Dimensions of Adult Learning. San Francisco, CA: Jossey-Bass.

Mueller, Robin. 2018. "Ensuring Design Alignment in SoTL Inquiry: Merging Research Purpose and Methods." In SoTL in Action: Illuminating Critical Moments of Practice, edited by Nancy Chick, 53-61. Sterling, VA: Stylus.

Miller-Young, Janice, and Michelle Yeo. 2015. "Conceptualizing and Communicating SoTL: A Framework for the Field." Teaching and Learning Inquiry 3, no. 2: 37-53. https://doi.org/10.20343/teachlearninqu.3.2.37.

Nilson, Linda B. 2013. Creating Self-Regulated Learners: Strategies to Strengthen Students' Self-Awareness and Learning Skills. Sterling, VA: Stylus.

Pace, David, and Joan Middendorf, eds. 2004. "Decoding the Disciplines: Helping Students Learn Disciplinary Ways of Thinking." New Directions for Teaching and Learning 98.

Potter, Michael K., and Erika D. H. Kustra. 2011. "The Relationship between Scholarly Teaching and SoTL." International Journal for the Scholarship of Teaching and Learning 5, no. 1: Article 23. http://www.georgiasouthern.edu/ijsotl.

Richlin, Laurie, and Milton D. Cox. 2004. "Developing Scholarly Teaching and the Scholarship of Teaching and Learning through Faculty Learning Communities." New Directions for Teaching and Learning 97: 12735. https://doi.org/10.1002/tl.139.

Ryan, Richard M., and Edward L. Deci. 2000. "Intrinsic and Extrinsic Motivations: Classic Definitions and New Directions." Contemporary Educational Psychology25, no. 1: 54-67. https://doi.org/10.1006/ceps.1999.1020.

Saldana, Johnny. 2013. The Coding Manual for Qualitative Researchers. $3^{\text {rd }}$ Ed. Sage. 
Schunk, Dale H. 2020. Learning Theories: An Educational Perspective Eighth Edition. Pearson.

Scott, David. 2013. Theories of Learning. Thousand Oaks, CA: Sage.

Tashakkori, Abbas, and John W. Creswell. 2007. "Exploring the Nature of Research Questions in Mixed Methods Research." Journal of Mixed Methods Research 1, no. 3: 207-211.

Thomas, Alison M. 2019. "Edging Towards Understanding: Illuminating Student Experiences of Liminality in Introductory Sociology." In Threshold Concepts on the Edge, edited by Julie A. Timmermans, and Ray Land,113-125 Leiden: Brill/Sense Publishers

Tight, Malcolm. 2017. "Tracking the Scholarship of Teaching and Learning." Policy Reviews in Higher Education 2, no. 1: 61-78. https://doi.org/10.1080/23322969.2017.1390690.

Wigfield, Allan, and Jacquelynne S. Eccles. 2000. "Expectancy-Value Theory of Achievement Motivation." Contemporary Educational Psychology 25, no. 1: 68-81. https://doi.org/10.1006/ceps.1999.1015. authors, and copyright for the publication layout resides with the journal. These copyright holders have agreed that this article should be available on open access under a Creative Commons Attribution License 4.0 International (https://creativecommons.org/licenses/by-nc/4.0/). The only constraint on reproduction and distribution, and the only role for copyright in this domain, should be to give authors control over the integrity of their work and the right to be properly acknowledged and cited, and to cite Teaching \& Learning Inquiry as the original place of publication. Readers are free to share these materials-as long as appropriate credit is given, a link to the license is provided, and any changes are indicated. 